\title{
Fixed drug eruption associated with anaesthesia
}

Joseph A. Bremang MD FRCP, ${ }^{*}$ Susan Halasi MSc Phm $\dagger$

We report the case of a 65-yr-old woman undergoing bronchoscopy for a lobular lesion who received thiopentone to induce anaesthesia that was maintained with sufentanil, vecuronium and isoflurane. She tolerated the procedure well initially, but developed eruptions about her face and fingers within 24 $\mathrm{hr}$ of anaesthesia. Treatment with flucinonide cream (0.05\%) resolved the eruptions with no lasting sequelae. Literature review supported the suspicion that the offending agent may have been thiopentone, so when a lobectomy was subsequently required and the patient refused investigation to identify the causative agent, propofol was employed as an alternative to induce anaesthesia. The surgery was well tolerated and the patient was discharged after an uneventful postoperative course. This case is reported to heighten awareness of the delayed onset of adverse effects which may be associated with the use of thiopentone.

Nous rapportons le cas d'une patiente de 65 ans porteuse d'une lésion lobulaire chez qui on pratique une bronchoscopie. La patiente reçoit du thiopentone, du sufentanil, du vécuronium et de lisoflurane. Elle tolère bien lintervention mais des éruptions apparaissent sur sa figure et sur ses doigts $24 \mathrm{~h}$ après l'anesthésie. Un traitement à la crême de flucinonide (0.05\%) guérit les éruptions sans laisser de séquelles. La revue de la litérature supporte lhypothèse selon laquelle le thiopentone serait l'agent causal; comme un lobectomie est jugée nécessaire par la suite, et que la patiente refuse toute investigation susceptible didentifier la cause de léruption, nous utilisons le propofol pour induire l'anesthésie. La chirurgie est bien tolérée

\section{Key words}

ANAESTHETICS, INTRAVENOUS: propofol, thiopentone; ANAESTHETICS, VOLATILE: isoflurane; COMPLICATIONS: fixed drug eruption.

From the Departments of Anaesthesia*, and Pharmaceutical Services†, St. Joseph's Health Centre, Toronto, Ontario, M6R $1 \mathrm{~B} 5$.

Address corresondence to: Susan Halasi, St. Joseph's Health Centre, 30 The Queensway, Toronto, Ontario M6R IB5. Accepted for publication 18th February, 1995. et l'évolution postopératoire se déroule sans incidents. Cette observation est présentée dans le but souligner quil faut toujours avoir à l'esprit la possibilité de répercussions délétères tardives induites par le thiopentone.

Thiopentone has occasionally been associated with anaphylaxis. ${ }^{1-4}$ Such an incident can be so catastrophic that there are several reports describing the use of either skin testing or radioimmunoassay (RIA) to avert anaphylaxis in subsequent surgery in these individuals or to confirm the drug as the major cause of death from a medicolegal standpoint. 5,6

A less well-documented event associated with thiopentone use is the eruption of discreet, well-demarcated plaques. ${ }^{78}$ Classically, these enuptions appear symmetrical, may be fluid-filled, are painful and erythematous. The lesions become evident within $24 \mathrm{hr}$ of drug administration and fade within a few weeks, leaving no trace. As the appearance of this adverse effect is delayed and its course self-limiting and non-fatal, anaesthetists are seldom aware a reaction has occurred.

This report describes a patient who developed such a fixed drug eruption within $24 \mathrm{hr}$ of receiving thiopentone anaesthesia while undergoing bronchoscopy. She subsequently required a lobectomy, necessitating the use of an alternative anaesthetic technique.

\section{Case report}

The patient, a 65-yr-old woman, ASA II, was referred for a bronchoscopy and biopsy. She had a 45-pack years smoking habit, drank considerably and was allergic to penicillin. The patient denied taking acetaminophen, codeine, tetracycline or sulphonamides in the weeks prior to surgery. For prophylaxis, she was prescribed vancomycin $500 \mathrm{mg} \dot{i}$. Premedication consisted of lorazepam $0.5 \mu \mathrm{g}$ sublingually and atropine $0.4 \mathrm{mg}$. Anaesthesia was induced with thiopentone $275 \mathrm{mg}$ and sufentanil 20 mg. Vecuronium $6 \mathrm{mg}$ was given to facilitate relaxation and $0.5-1 \%$ isoflurane to maintain anaesthesia. The patient tolerated the $30 \mathrm{~min}$ procedure well, left the recovery suite in good condition and was discharged from the hospital that evening. 
The next day, the patient travelled to Florida and during the flight, her fingers became swollen, erythematous and developed fluid-filled vesicles (Figure 1). By the time she reached her destination, her fingers were immobile and blisters were erupting temporally and periorbitally about the face. A local dermatologist diagnosed a toxic drug reaction from an unknown agent and prescribed flucinonide cream $0.05 \%$. Application of cream improved the condition of her hands and face to the point that there was no noticeable scarring but only a residual demarcation of the affected area seven days later (Figure 2).

The woman returned home and was admitted for probable lobectomy. Glycopyrrolate $0.2 \mu \mathrm{g}$ was employed for premedication, anaesthesia was induced with propofol $100 \mathrm{mg}$ and fentanyl given to a total of $200 \mu \mathrm{g}$. Pancuronium $5 \mathrm{mg}$ facilitated intubation and anaesthesia was maintained with $1-2 \%$ isoflurane. The patient tolerated the procedure well and was transferred to the Acute Care Unit for postoperative care. Following a rapid recovery and no adverse sequelae from medications administered, the patient was discharged home.

\section{Discussion}

The close temporal association between anaesthesia and the fixed drug eruption suggests that one of the agents used was responsible. Since no documented cases of such a reaction occurring with the use of vecuronium, sufentanil or isoflurane could be found, the implication was that thiopentone may have been the causative agent. In addition, the patient denied using any agents ${ }^{8}$ notorious for precipitating this type of reaction in the week prior to surgery.

Desmeules ${ }^{8}$ described a non-pigmenting, fixed drug eruption which he attributed to the use of thiopentone. Our patient's detailed description and informative photographs of her experience, which closely matched Desmeules' report, coupled with the provisional diagnosis presumed by the dermatologist of fixed drug eruption, heightened our suspicion. Butler $e t a l^{7}$ also reported the eruption of skin lesions on the hands, arms and legs of a patient who received thiopentone anaesthesia. In neither report was the patient challenged with thiopentone to confirm allergy, although both authors felt that testing would establish proof. The practitioners were reluctant to have their patients undergo any further discomfort.

Our patient would not consent to skin testing (either prick or intradermal), to confirm sensitivity to thiopentone before the second operation. Fisher et al. ${ }^{6}$ suggest examining sera for the presence of specific immunoglobulin E (IgE) antibodies in cases of anaphylaxis. In such cases, patients' reactions are characterized by cardiovas-

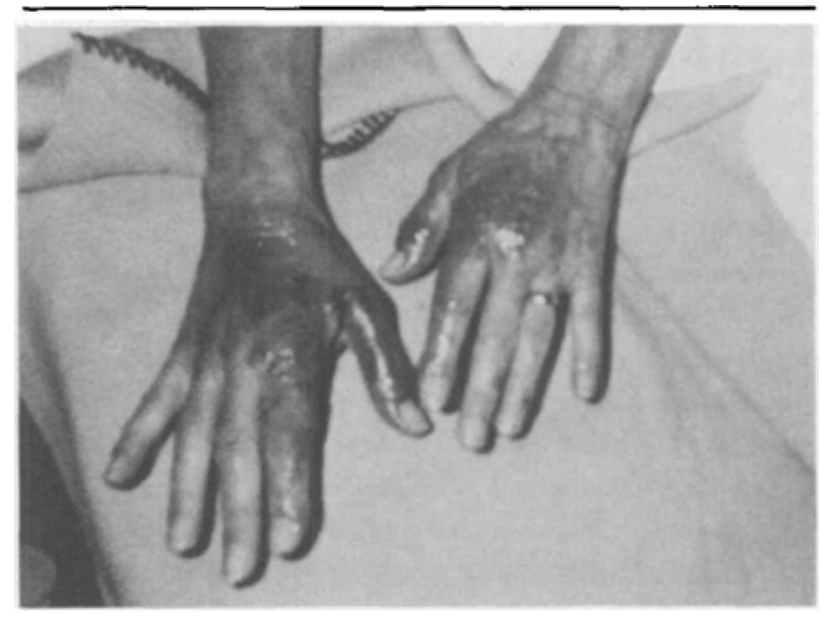

FIGURE 1 Oedematous fingers covered in fluid-filled cysts less than $48 \mathrm{hr}$ after anaesthesia.

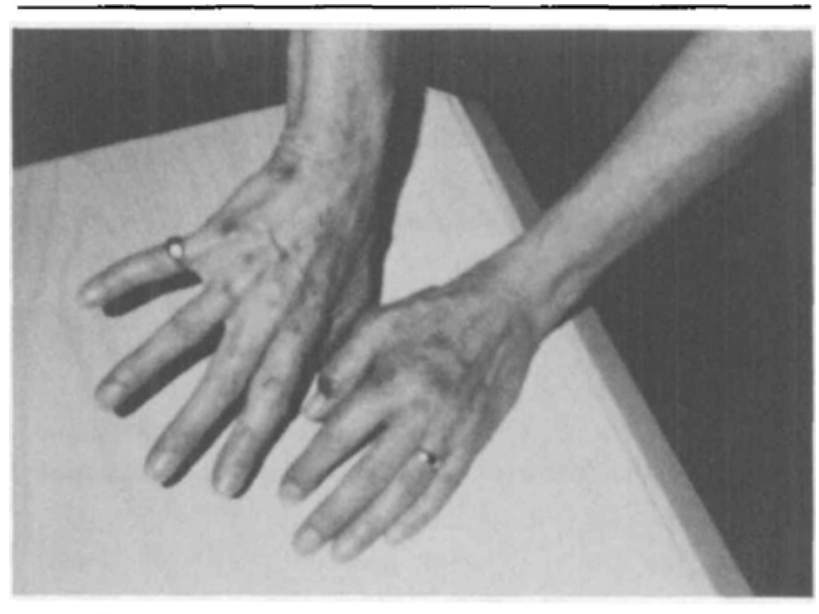

FIGURE 2 Appearance of fingers after one week of treatment with flucinonide cream $(0.05 \%)$. Note darkened areas about the cuticles and knuckles which were once vesicular plaques.

cular collapse, bronchospasm, generalized urticaria and lobster-red skin, ${ }^{1-3}$ so a confirmation of hypersensitivity is imperative. In our patient's case, the reaction was localized. Nevertheless, some guidance in management for subsequent surgery was desirable. Williamson ${ }^{9}$ described the successful use of propofol in a 30-yr-old woman who had had a previous anaphylactic response to thiopentone. $\mathrm{He}$ mentioned that there was no existing evidence of cross-allergy between the two drugs.

This case is documented to increase awareness that fixed drug eruptions can be associated with anaesthesia. Though rare, this delayed onset reaction may be underreported ${ }^{7,8}$ as the physician prescribing the offending 
agent is usually not the one who is later called upon to make the diagnosis. Once recognized, further patient discomfort can be prevented by excluding the precipitating agent in future techniques.

\section{References}

1 Dundee JW, Assem ESK, Gaston JM, et al. Sensitivity to intravenous anaesthetics: a report of three cases. BMJ 1974; 1: 63-5.

2 Dolovich J, Evans $S$, Rosenbloom $D$, Goodacre $R, R a$ fajac $F O$. Anaphylaxis due to thiopental sodium anesthesia. Can Med Assoc J 1980; 123: 292-4.

3 Moneret-Vautrin DA, Widmer S, Gueant J-L, et al. Simultaneous anaphylaxis to thiopentone and a neuromuscular blocker: a study of two cases. Br J Anaesth 1990; 64: 743-5.

4 Assem ESK. Anaphylactic anaesthetic reactions. Anaesthesia 1990; 45: 1032-8.

5 Baldo $B A$, Fisher $M M$, Harle $D G$. Allergy to thiopentone. Clin Rev Allergy 1991; 9: 295-308.

6 Fisher MM, Baldo BA, Silbert BS. Anaphylaxis during anesthesia: use of radioimmunoassays to determine etiology and drugs responsible in fatal cases. Anesthesiology 1991; 75: 1112-5.

7 Butler JM, Kazmierowski JA, Bruss RD, Hirshman CA. An unusual adverse drug reaction to thiopental. Anesthesiology 1982; 57: 51-3.

8 Desmeules $H$. Nonpigmenting fixed drug eruption after anesthesia. Anesth Analg 1990; 70: 216-7.

9 Williamson J. Safe induction with propofol following thiopentone anaphylaxis (Letter). Anaesth Intensive Care 1990; 18: $277-8$. 